Original article

\title{
Sociodemographic, biological and cultural factors affecting morbidities among infants: A longitudinal study in rural Karnataka
}

\author{
Vijayashree Mathad $^{\mathrm{a}, *}$, Vijaya Naik ${ }^{\mathrm{b}}$, N.S. Mahantashetti ${ }^{\mathrm{c}}$ \\ ${ }^{a}$ Narayana Health CSR, Kalaburagi, India \\ ${ }^{\mathrm{b}}$ Retired Professor Community Medicine and Head Department of Public Health JN Medical College, Belagavi, India \\ ${ }^{\mathrm{c}}$ Professor Pediatrics and Principal JN Medical College, Belagavi, India
}

\section{A R T I C L E I N F O}

\section{Keywords:}

Morbidity

Infants

Socio demographic profile

Cultural practices

Longitudinal study

\begin{abstract}
A B S T R A C T
Background: Morbidities during infancy have a deadly effect on growth and development among infants. Globally, more than 0.5 million newborns die a year due to morbidities. In India, fifty percent of them are underweight.

Objectives: To study morbidities during first year of life and to assess socio-demographic, biological and cultural factors influencing morbidity during first year of life.

Methodology: This Longitudinal study was carried out in rural community of Kinaye, Vantamuri and Handignur PHC. Study population constituted of Babies born during May 2013-March 2014. Sample size was calculated and 962 infants were enrolled by using random number tables. Data was obtained from mothers using semi structured pretested questionnaire. The baseline data was collected within first week of the birth and were followed up monthly till the child completes 1 year. Descriptive statistics and inferential statistics were used for analysis. Results: The incidence of morbidities during first year of life was 14.18 episodes per child-year. The incidence of Acute respiratory infections, Diarrhea and Fever during twelfth month was 0.31/infant-year, 0.25/infant-year and 0.22/infant-year. The socio demographic factors associated with Morbidities were non working (AOR: 1.320) illiteracy (AOR: 1.964) among mothers from low socio economic status (AOR: 1.651), Biological factors associated were low Gestational age (AOR: 2.594), No ANC registration (AOR: 3.047) and Low birth weight (AOR: 1.771). Cultural factors associated were Delayed initiation of breast feeding (AOR: 2.284) and Delayed bathing (AOR: 1.383).

Conclusion: Improving female literacy and employment plays a major role in alleviating the morbidity among infants in rural areas.
\end{abstract}

\section{Introduction}

Today's child is tomorrow's hope, Children are precious and are crown jewels not only of the family but also of nation. Their development is also the development of the nation as a whole. As the saying goes, home is the first school for the child and mother is the first teacher, hence the cultural and behavioural practices of the parents are passed on to their progeny. Globally, over five lakh newborns die of serious infections and majority of these deaths occur in developing countries as compared to developed countries. ${ }^{1}$ The mortality and morbidity among infants and mothers can be controlled by skilled attendants and skilled care. Accessibility to quality health care during ante and postnatal care is crucial to reducing these. ${ }^{1}$ More than $98 \%$ of neonatal deaths occur in developing countries, their major cause being infections accounting for $37 \%$, followed by birth asphyxia and congenital anomalies. ${ }^{2}$ Morbidities during infancy have a deadly effect on growth and development among infants. Globally, more than 0.5 million newborns die a year due to morbidities during neonatal period and 9 to 10 million under-five die yearly,. ${ }^{3,4}$ Longitudinal studies are more advantageous since it is useful to observe the morbidity pattern of infants over a duration of time. ${ }^{5}$ Environmental factors have a major role as compared to biological factors in influencing the morbidity of infants. But no such studies have been carried out in India to assess the effect of all the factors together on morbidity among infants.

\footnotetext{
* Corresponding author.

E-mail address: vijayashreemathad@yahoo.in (V. Mathad).
} 


\section{Methodology}

This was a Observational, descriptive study adopting longitudinal study design carried out in rural area of Belagavi district. Babies born during study period in the all three Primary Health Centers which fit the inclusion criteria were enrolled in the study. Only the infants who were followed till the completion of 1 year were taken for analysis. Considering annual birth rate of May 19,1000/year as per the SRS data, approximately 160 babies (substracting 15\% attrition) were born per months in our study area. Sample size was calculated using the formula: $\mathrm{N}=\left(\mathrm{Z}_{1-\alpha}\right)^{2} \mathrm{x} \mathrm{pq} / \mathrm{d}^{2}$ Prevalence of ARI (p): 28.8. Prevalence of normal health(q): 100-p: 71.2 Standard Normal variate $\left(\mathrm{Z}_{1-\alpha)}: 1.96\right.$, Tolerable error (d):3\%. Sample required. $\mathrm{n}=\left[(1.96)^{2} \times 28.8^{*} 71.2\right] / 3^{2}=875.27$ $=875$. Adding $10 \%$ attrition rate. Sample Size $=963$.

963 babies born were selected using random number table and followed up from birth till 1 year at a interval of 1 month. The infants born were numbered in 3 digits starting from 001 to 244 who fit into inclusion criteria. A three digit random number was generated from random number table and followed column wise till the desired enrollment. The number greater than 244 was skipped. Every month Random number table was used for enrollment of babies till we got the desired number i.e 963. The enrollment was continued till the subsequent month.

\subsection{Inclusion criteria}

Singleton live born babies. Whose weight at birth was recorded and is more than 1500 gms, with no congenital abnormalities and mothers have been residing in PHC areas for at least 6 months, before the commencement of study; Infants available for study from birth till 1 year.

\subsection{Exclusion criteria}

Were Multiple births and Home deliveries.

Detailed information like types of morbidities, duration of morbidities were collected using detailed interview technique. Questionnaire was used to collect data pertaining to socio demographic and obstetric history whereas interview schedule was used to obtain data pertaining to feeding practices, morbidities and cultural practices. The baseline data was collected within first week of the birth. Every neonate enrolled were followed up at monthly intervals till the child completes 1 year. During the follow up visits, data regarding infants feeding and cultural practices, morbidity in the earlier month and immunization were obtained. Anganwadi workers were trained to collect the data.

The results were presented with appropriate tables, graphs and narrative forms. Descriptive and inferential statistics were used for analysis of data. Descriptive statistics used were frequency, mean, standard deviation, percentage, median and range. Inferential statistics used for analysis were Chi square test, $\mathrm{Z}$ scores, correlation and binary logistic regression models. Logistic regression model was used to check the relationship of socio demographic, maternal and cultural factors affecting morbidity. Odds ratio and $\mathrm{P}$ value was used to check the association. $\mathrm{P}$ value $<0.05$ was considered significant.

Ethical clearance was obtained from Institutional Ethical Committee of KLE University Belgavi before the commencement of research. Informed consent was obtained from the study participants.

\section{Results}

A total of 962 new born were enrolled in our study. 37 infants were loss to follow up, whereas a total of 925 infants were followed for 1 year duration. 925 infants enrolled were analyzed as per the objectives. Out of 925 mothers, majority of the mothers belonged to age group of 19-30 years. Teenage pregnancy was seen among $4 \%$ of mothers. Mean Age of the Mothers was $24.76 \pm 3.914$.As per the age at first pregnancy, 24 of them had first pregnancy before the age of $18 \mathrm{yrs}$, whereas $72 \%$ had pregnancy during the 19-20 years.

In our study majority of mothers were house wives (62\%) and $25 \%$ of Mothers worked as cooli.16\% of the mothers were illiterate whereas $41.6 \%$ of mothers had completed secondary education. The mean age of father was $29.43 \pm 3.363$. Around $34 \%$ of fathers worked on daily wages while $30 \%$ of them practiced farming.

$51 \%$ were Hindu followed by Muslim comprising 32\%. According to the family size, $53 \%$ of the family had more than 6 members in the family, whereas 42 families had 1 to 3 members. In our study majority of the family belonged to class III socio economic status compromising $40 \%$ followed by class II $32 \%$. About $48 \%$ infants belonged to third generation family whereas $37 \%$ of infants belonged to nuclear family. Only $15 \%$ belonged to joint family.

$95 \%$ of women had ANC registered. $52 \%$ of women had 4 to 6 ANC visit and $26 \%$ of women had more than 6 ANC visits. $61 \%$ of women had consumed 100 to 200 IFA tablets during ANC and $86 \%$ of women had received the appropriate doses of Tetanus injections. $76 \%$ of infants were born through vaginal delivery and $24 \%$ of infants were born through caesarean section.

Out of 925 infants $54 \%$ were male. All the infants were given neonatal vaccinations like OPV, BCG and Hep B at birth. $21 \%$ of infants were born without proper birth spacing of 2 years, whereas $76 \%$ of infants were born with proper birth spacing of $2-5$ years. Majority $53 \%$ of infants belonged to more than third birth order. $6 \%$ of infants birth weight was between 1800 and 2000 gms and $11 \%$ of infants birth weight was between 2100 and 2400 gms. The mean birth weight of infants being $2.85 \pm 0.365$.

$79 \%$ of infants were started with breast feeding within 30 min of birth. 7\% of women stated feeding between 31 and $60 \mathrm{~min}$ of time, whereas $14 \%$ infants initiated breast feeding after $8 \mathrm{~h}$ of birth. Colostrum was given to $96 \%$ infants. Prelacteal feeds was given among $15 \%$ of infants. $88 \%$ of mothers followed demand feeding whereas $4 \%$ were exclusively breast feed for less than 3 months. $85 \%$ of infants were exclusively breast fed for 6 months and more.

The total numbers of episodes of morbidities during first year of life were 13120 . The incidence rate of morbidities during 1 st year of life was 14.18 episodes per child-year during the 1st year of life. Our study revealed incidence of ARI being 3.21/infant year. Diarrhea incidence being 2.88/infant year, fever incidence being 2.54/infant year. The incidence of ARI was slightly more (1.73 episodes per infant) during second six months of life. The incidence of Diarrhea was drastically increased during second six months of life (2.09 episodes per infant) as compared to 0.9 episodes per infant during first six month of life this can be attributed to poor feeding practices.

The incidence of fever was also slightly more during second six months of life. The incidence of fever during second six months of life was 1.34 episodes per infant, more as compared during first six months of life. The incidence of other morbidities like otitis media, conjunctivitis, acute rhinitis and other infection were decreased during second six months of life. The incidence being $0.34,0.34,0.21$ and 0.03 episodes per infant respectively(Fig. 1).

\subsection{Socio-demographic profile affecting morbidity among infants}

As per the socio-demographic profile the factors that were significantly associated with ARI were mothers occupation ( $p=0.015$ ), Educational status of mothers $(\mathrm{p}=0.004)$, and socio economic status ( $\mathrm{p}$ $=0.001$ ). The factors significantly associated with incidence of diarrhea were religion $(p=0.009)$ and socio economic status $(p=0.006)$. The factors significantly associated with fever were mothers occupation $(\mathrm{p}=$ $0.012)$, mothers education $(\mathrm{p}=0.001)$ and fathers education $(\mathrm{p}=$ 0.033) (Table 1).

\subsection{Biological factors affecting morbidity among infants}

As per the biological profile, the factors that were significantly 


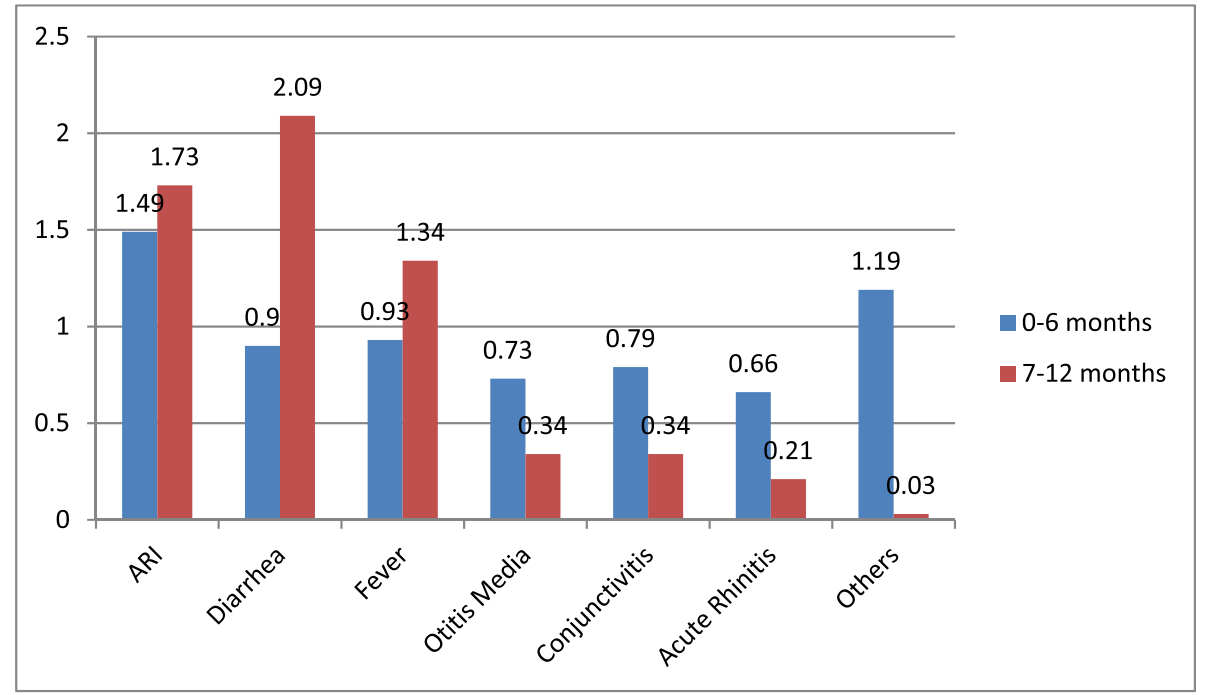

Fig. 1. Diagram representing the incidence of morbidities among infants.

Table 1

Socio demographic, biological and cultural factors associated with morbidity among infants.

\begin{tabular}{|c|c|c|c|}
\hline Variable & $\begin{array}{l}\text { ARI } \\
\text { Episodes }\end{array}$ & $\begin{array}{l}\text { Diarrhea } \\
\text { Episodes }\end{array}$ & $\begin{array}{l}\text { Fever } \\
\text { Episodes }\end{array}$ \\
\hline \multicolumn{4}{|l|}{ Mothers Occupation } \\
\hline Housewife $\mathrm{N}=606$ & 168 & 77 & 322 \\
\hline Working $\mathrm{N}=319$ & 67 & 50 & 144 \\
\hline$\chi^{2}, \mathrm{Df}, \mathrm{P}, \mathrm{OR}$ & $4.979,1, \mathbf{0 . 0 1 5}, 1.320$ & $1.554,1,0.126,1.035$ & $5.343,1,0.012,1.177$ \\
\hline \multicolumn{4}{|l|}{ Mother Education } \\
\hline Illiterate $\mathrm{N}=150$ & 24 & 25 & 57 \\
\hline Literate $\mathrm{N}=775$ & 211 & 102 & 366 \\
\hline$\chi^{2}, \mathrm{Df}, \mathrm{P}, \mathrm{OR}$ & $8.357,1,0.004,1.964$ & $1.304,1,0.156,1.266$ & $10.973,1,0.001,1.823$ \\
\hline \multicolumn{4}{|l|}{ Fathers Education } \\
\hline Illiterate $\mathrm{N}=140$ & 43 & 16 & 81 \\
\hline Literate $\mathrm{N}=785$ & 192 & 111 & 385 \\
\hline$\chi^{2}$ Df, P,OR & $2.453,1,0.074,1.256$ & $0.738,1,0.237,1.276$ & $3.691,1,0.033,1.180$ \\
\hline \multicolumn{4}{|l|}{ Socio- Economic Status } \\
\hline Class III, IV and V N $=376$ & 75 & 65 & 181 \\
\hline Class I and II N = 549 & 160 & 62 & 285 \\
\hline$\chi^{2}, \mathrm{Df}, \mathrm{P}, \mathrm{OR}$ & $9.961,1,0.001,1.651$ & $6.769,1,0.006,1.531$ & $1.272,1,0.144,1.163$ \\
\hline \multicolumn{4}{|l|}{ Gestational Week } \\
\hline$\leq 37$ Weeks $\mathrm{N}=182$ & 88 & 23 & 79 \\
\hline$>37$ Weeks $N=743$ & 197 & 104 & 367 \\
\hline$\chi^{2}, \mathrm{Df}, \mathrm{P}, \mathrm{OR}$ & $32.70,1,<0.001,2.594$ & $0.228,1,0.366,1.125$ & $4.406,1,0.022,1.417$ \\
\hline \multicolumn{4}{|l|}{ IFA tablets } \\
\hline$<100$ tablets $\mathrm{N}=370$ & 282 & 118 & 191 \\
\hline$\chi^{2}, \mathrm{Df}, \mathrm{P}, \mathrm{OR}$ & $220.76,1,<0.001,8.89$ & $45.413,1,<0.001,2.996$ & $29.526,1,<0.001,2.09$ \\
\hline \multicolumn{4}{|l|}{ Sex } \\
\hline Male $\mathrm{N}=502$ & 229 & 169 & 260 \\
\hline Female $\mathrm{N}=423$ & 106 & 108 & 206 \\
\hline$\chi^{2}, \mathrm{Df}, \mathrm{P}, \mathrm{OR}$ & $42.00,1,<0.001,2.508$ & $7.23,1,0.007,1.48$ & $0.879,1,0.192,1.064$ \\
\hline \multicolumn{4}{|l|}{ Birth Weight } \\
\hline$<2500 \mathrm{gms} \mathrm{N}=156$ & 27 & 16 & 65 \\
\hline$\chi^{2}, \mathrm{Df}, \mathrm{P}, \mathrm{OR}$ & $6.493,1,0.006,1.771$ & $1.911,1,0.102,1.476$ & $5.697,1,0.011,1.526$ \\
\hline \multicolumn{4}{|l|}{ Umbilical oil application } \\
\hline Yes $N=245$ & 73 & 24 & 136 \\
\hline$\chi^{2}, \mathrm{Df}, \mathrm{P}, \mathrm{OR}$ & $3.390,1,0.041,1.251$ & $4.354,1,0.022,1.644$ & $3.511,1,0.036,1.144$ \\
\hline
\end{tabular}

associated with ARI were Gestational week ( $\mathrm{p}<0.001)$, Birth order $(\mathrm{p}=$ 0.03 ), consumption of IFA tablets ( $<0.001$ ), Sex of the new born ( $<<$ $0.001)$ and birth weight $(\mathrm{p}=0.006)$. The factors significantly associated with incidence of diarrhea were type of delivery $(\mathrm{p}=0.02)$, ANC registration $(p=0.05)$, Consumption of IFA tablets $(p<0.001)$ and Sex of newborn $(p=0.007)$. The factors significantly associated with incidence of fever were weeks of gestation $(\mathrm{p}=0.022)$, Consumption of IFA tablets $(\mathrm{p}<0.001)$ and birth weight $(\mathrm{p}=0.011)$ (Table 1$)$.

\subsection{Impact of cultural factors on morbidity among infants}

As per the cultural and feeding factors that were significantly associated with ARI were initiation of breast feeding $(\mathrm{p}=0.016)$, application of oil to umbilicus ( $\mathrm{p}=0.041$ ), bathing within $24 \mathrm{~h}$ of birth $(\mathrm{p}=0.048)$, and application of black carbon to inner cantus $(\mathrm{p}=0.041)$. The factors significantly associated with incidence of diarrhea were application of oil to umbilicus $(\mathrm{p}=0.022)$ and application of black carbon to inner canthus ( $\mathrm{p}=0.022$ ). The factors significantly associated with incidence 
of fever were application of oil to umbilicus $(\mathrm{p}=0.036)$, bathing within $24 \mathrm{~h}$ of birth $(\mathrm{p}=0.022)$ and application of black carbon to inner cantus $(p=0.036)$ and depositing of oil drops into ears $(p=0.048)$ (Table 1$)$.

\section{Discussion}

Infancy is an important stage in childhood growth and development, and numerous landmark programmes have been set in place to improve their survival and growth. Some of the major programmes include Reproductive, Maternal, Newborn Child and Adolescent Health $(\mathrm{RMNCH}+\mathrm{A})$ strategy, National Health Mission (NHM) and ICDS (Integrated Child Development Services). NHM program focuses on the provision of resources for newborn's health, whereas RMNCH $+\mathrm{A}$ and ICDS are devoted to the continuation of the care model to health and nutritional status of infants, children and adolescents. Morbidities like ARI, Diarrhea and fever have a serious effect on the infant's nutritional status and development leading to reduced appetite, underweight, stunting and wasting. Diarrhea is significantly associated with underweight and ARI has a chronic impact on stunting among children.

The study revealed that the incidence of Diarrhea increased steadily during the second half of infancy, and ARI and fever were high during the neonatal period and the first six months of life. Our results are similar to a study in rural areas of Jammu, where the incidence of ARI and Diarrhea was the same compared to fever. ${ }^{8}$ In various studies in Guntur and south India, the incidence of morbidities like ARI and Diarrhea was more common during the second six months of life. ${ }^{7,8}$ The increased incidence of morbidities during the second six months of life may be attributed to faulty feeding practices like inappropriate exclusive breast feeding, improper weaning and cultural practices leading to malnutrition and increased morbidities. ${ }^{9}$

The cultural and feeding factors that were significantly associated were initiation of breastfeeding, application of oil to umbilicus, bathing within $24 \mathrm{~h}$ of birth, and application of black carbon to inner canthus. A study in Jammu revealed that the annual incidence of morbidity was 4.6/child -year. The incidence was more of ARI and Diarrhea and was more associated with the female sex, malnourishment and infancy. No association was seen with parental literacy status. ${ }^{7}$ A longitudinal study in Guntur showed that morbidities were more during the second six months of infancy as compared to the first six months. The incidence of morbidities was significantly associated with poor feeding practices. ${ }^{8}$

Breastfeeding had a protective effect on the incidence of morbidity among infants. Lower odds ratio of morbidities was seen among the infants who were exclusively breastfed. Income was not associated with the incidence of morbidities. Infants with siblings had significantly increased incidence of morbidities as compared with those with no siblings. ${ }^{9}$ A longitudinal study in Dundee revealed that the infants who were breastfed for 13 weeks or more had less incidence of morbidity as compared to those who were breastfed for less than 13 weeks. ${ }^{10}$ Another longitudinal study on the effect of feeding practices on infant's health showed that the factors significantly associated with the infant's health and the incidence of morbidities were inappropriate exclusive breastfeeding and sanitation. Introduction of water during the first six months was also significantly associated with increased incidence of morbidities. ${ }^{11}$

Longitudinal studies in Delhi and south India among infants revealed that the morbidity rate was low during the first six months as compared to the next six months. There was positive correlation among socioeconomic status, literacy rate and the sex of the infants. ${ }^{2,3,12,13}$ Longitudinal studies in semi-urban areas and the Safdurjung Hospital in New Delhi and Hadassah Hospital in Jeruselam revealed that morbidity was more during the first half of infancy than in the second half. The majority of illnesses were due to RTI and diarrhea. The incidence was found to decrease with rise in family income and proper feeding practices. $^{14,15,16}$

A longitudinal study in Aligarh among infants to study the morbidity pattern and feeding practices showed that top-fed infants had more incidence of RTI, diarrhea, severe malnutrition, anemia and Vitamin A deficiency. The incidence of RTI among artificially fed infants showed an abrupt increase after six months of age. ${ }^{17,18} \mathrm{~A}$ prospective study at Vajjra Hospital in Thialand revealed that iron-deficiency anemia was significantly higher among formula-fed infants. ${ }^{19,20}$

A one-year longitudinal study conducted among Malawian infants during March 2006 with monthly visits to assess morbidity and growth parameters revealed that the infants with early complementary feeding were significantly associated with increased risk of RTI. ${ }^{21,22}$ A cross-sectional study on infant feeding and rearing practices among rural and urban infants of Jammu including various faulty feeding practices showed delayed initiation of breastfeeding, administration of prelacteal feeds and early weaning practices. All these factors contribute to an increased incidence of diarrhea and vomitting. ${ }^{23,24}$

Faulty feeding practices were seen in a study carried out in the rural areas of Pondicherry and Jammu on infant feeding and rearing practices. These included delayed initiation of breast feed, and rearing practices like instillation of oil into eyes, nose, ears and mouth which led to morbidity among infants. Diarrhea and vomiting occurred with greater frequency among the top-fed infants. ${ }^{6,26}$

\section{Conclusion}

The incidence of ARI, Diarrhea and fever among infants in our study was quite less as compared to the national figures of these morbidities among under five children. Morbidities were significantly high during second six month of life due to inappropriate feeding practices. Improving female literacy and employment plays a major role in alleviating the morbidity.

\section{Declarations}

Funding

None.

\section{Ethical approval}

Obtained.

\section{Declaration of competing interest}

None.

\section{Acknowledgement}

We are very thankful and grateful to late Dr. MD Mallapur statistician for his constant support in statistical analysis without his support the present analysis was next to impossible.

\section{References}

1 Ajay K. Primary newborn care health action. Ann Med Health Sci Res. 2016;6(1): 27-32.

2 Gupta MK, Munish K, Sethi C, Malhotra AK. Pattern of morbidity and mortality in LBW neonates: a study from Jaipur. J Evol Med Dent Sci. 2014;3(6):1139-1145.

3 Richard LG. Malnutrition as an enteric infectious disease with long-term effects on child development. Nutr Rev. PMC. 2009 September;1:1-33.

4 Acharya D, Paudel A, Gautam S, Upadhyaya T. Knowledge of maternal and newborn care among primary level health workers in kapilvastu district of Nepal. Ann Med Health Sci Res. 2016 Jan-Feb;6(1):27-32.

5 Madhur B, Rupali B. Morbidity status of low birth weight babies in rural areas of Assam: a prospective longitudinal study. J Fam Med Prim Care. 2015;4(3):380-383.

6 Gupta Sanjana, Jamwal DS, Kumar Dinesh, Gupta SK. Morbidity among Under Five Children in a Rural Area of Jammu. April - June 2012;Vol. 14(2):85-88.

7 Sreedevi B, Nageswara R. A Longitudinal Study on Feeding Practices and Morbidity Patterns of Infants in A Rural Field Practice Area of Thadikonda. Guntur www.iosrjou rnals.org. Accessed March , 2015, 36-39. 
8 Vijayalaxmi S, Patil R, Datta SS, Narayan NA, Stephen F. Feeding practices and morbidity pattern of infants in a rural area of puducherry- a Follow up study. J Community Med Health Educ. 2014;4:4.

9 Melo MC, Taddei JA, Diniz-Santos DR, et al. Incidence of diarrhea in children living in urban slums in Salvador, Brazil. Braz J Infect Dis. 2008;12(1):89-93.

10 Peter Howie W, Stewart Forsyth J, Simon Ogston A, Clark Ann, Charles du Florey V. Protective effect of breast feeding against infection. BMJ Jan. 1990;Vol 300:11-16.

11 Deb SK. Acute respiratory disease survey in Tripura in case of children below five years of age. J Indian Med Assoc. 1998;96(4):111-116.

12 Datta N, Krishna R, Mane SIS, Lila R. Longitudinal study on morbidity and mortality pattern of children in Delhi during the first two years of life: a review of 1000 children. Indian J Med Res. 1967 May;55(5):504-512.

13 Nitin J, Subba SH, Vijaya AN, Mahantshetti NS, Mallapur MD. Morbidity among infants in south India: a longitudinal study. Indian J Pediatr. April, 2010;Volume 77: 456-458.

14 Sabrina N, Andrew Page, Kingsley EA. Household air pollution from use of cooking fuel and under-five mortality: the role of breastfeeding status and kitchen location in Pakistan PLOS ONE |/journal.pone. Assessed on March 2016.

15 Deaton A, Jean D. Food and Nutrition in India: Facts and Interpretations Economic \& Political Weekly. 2009;14(7):42-65. february 14.

16 The Impact of Malnutrition on Children's Physical and Mental Development; May 2013, 2th www.kidscoplatepledge.org.

17 Koletzko B, Lien E, Agostoni C, et al. The roles of long-chain polyunsaturated fatty acids in pregnancy, lactation and infancy: review of current knowledge and consensus recommendations. J Perinat Med. 2008;36:5-14.
18 Jaiswal OP, Malik Ashraf, Ansari Z, Sinha SN. Study of feeding practices and morbidity pattern during first year of life. Indian Pediatr. Oct 1981:735-741.

19 Larque E, Gil SA, Prieto S, Koletzko B. Omega 3 fatty acids, gestation and pregnancy outcomes. Br J Nutr. 2012;107:S77-S84.

20 Tantracheewathorn S, Lohajaroensub S. Incidence and risk factors of iron deficiency anemia in term infants. $J$ Med Assoc Thai Jan. 2005;88(1):45-51.

21 Makrides M, Duley L, Olsen SF. Marine oil, other prostaglandin precursor, supplementation for pregnancy uncomplicated by pre-eclampsia or intrauterine growth restriction. Cochrane Database Syst Rev. 2006:75.

22 Kalanda BF, Verhoeff FH, Brabin BJ. Breast and complementary feeding practices in relation to morbidity and growth in Malawian infants. Eur J Clin Nutr. March. 2006; 60(3):401-407.

23 Ramakrishnan U, Stein AD, Parra-Cabrera S, et al. Effects of docosahexaenoic acid supplementation during pregnancy on gestational age and size at birth: randomized, double-blind, placebo-controlled trial in Mexico. Food Nutr Bull. 2010;31:108-116.

24 Narayanmurthy MR, Siddalingappa H, Kulkarni P, Ashok NC. Prevalence and determinants of low birth weight in rural Mysore. Int J Health Sci Res. 2013;3(8): $35-39$.

26 Edmond M K, Zandoh C, Quigley A M, Amenga S Etego, Owusu S Agvei, Kirkwood R B. Delayed breastfeeding initiation increases risk of neonatal mortality. Pediatrics. 2006 Mar;117(3):e380-e386. https://doi.org/10.1542/peds.2005-1496. PMID: 16510618. Pediatrics. 2006;117(3):380-386. 16510618. doi:10.1542/ peds.2005-1496. In press. 